\title{
Per què vols ser mestre? Com és un bon mestre? Idees per a la formació universitària
}

\section{Teodor Mellen Vinagre*}

\section{Resum}

Aquest treball es centra en un collectiu que s'està formant com a mestre; concretament analitza els estudiants del Grau d'Educació Primària de les universitats catalanes. Es presenten els resultats que s'obtenen quan se'ls pregunta per què volen ser mestres i com és un bon mestre. Es mostren també algunes consideracions rellevants per a la formació de mestres a la universitat d'avui. S'utilitza la metodologia quantitativa a través d'un qüestionari autoadministrat a una mostra representativa amb preguntes obertes i recodificades a posteriori. A partir de les investigacions de major incidència es construeixen tres categories principals. La primera és el mestre personal i autèntic, entenent per això el mestre que exerceix una influencia entre els seus estudiants pel seu caràcter o manera de ser; la segona és el mestre transmissor d'històries, referit al mestre que explica les lliçons d'una manera que difícilment s'oblida; i la tercera és el mestre motivador per l'aprenentatge, que fa referència a aquell mestre que organitza espais i moments en què l'alumnat aconsegueix aprendre amb certa facilitat i entusiasme. Aquesta evidència, justament amb d'altres que la complementen, permet oferir algunes consideracions útils per a la formació universitària dels futurs mestres.

\section{Paraules clau}

Formació universitària, Espai Europeu d'Educació Superior (EEES), grau d'educació primària, influència educativa.

Recepció original: 14 de març de 2019

Acceptació: 04 de setembre de 2019

Publicació: 20 de gener de 2020

\section{Introducció ${ }^{1}$}

És difícil imaginar una comunitat que hagi aconseguit un cert grau de desenvolupament sense tenir en compte els seus mestres² (Jaeger, 1981). Aquesta suposició no es refereix només al fet que un poble que aspira a créixer requereix, per exemple, un bon nombre de mestres, bones polítiques educatives o òptimes condicions laborals, sinó que apunta també, principalment, al fet que precisa dels millors mestres possibles. Pràcticament qualsevol persona podria dir alguna cosa interessant de

$\left(^{*}\right.$ Doctor en Sociologia, especialitzat en les tècniques i els mètodes de la investigació social, és investigador de la Càtedra Lideratges i Governança Democràtica d'ESADE. Els seus Interessos d'investigació es centren en els processos de canvi social, el sector no lucratiu i els processos de canvi educatiu. Adreça electrònica: teodor.mellen@esade.edu

(1) Aquest treball és part d'una investigació subvencionada per l'Agència Catalana d'Universitats i Recerca (AGAUR) en la convocatòria competitiva ARMIF 2014. Els membres del grup de recerca són: Francisco Esteban (IP), Isabel Carrillo. Josep Gustems, Carlota Bujons, Marta Burguet, Maria Rosa Buxarrais, Teodor Mellen, Montserrat Puigbarraca, Ana Teixidó i Isabel Vilafranca.

(2) Per una qüestió de claredat expositiva, ens referim a mestre, mestres, alumne, alumnes, etc., encara que òbviament, amb això també ens referim a mestra, mestres, alumna, alumnes, etc. 
quins mestres necessitem. No obstant això hi ha un colllectiu de persones que mereix tota la nostra atenció: aquelles que volen ser mestre. Quines raons porten a voler exercir un paper amb tanta rellevància? Com ha de ser un bon mestre segons aquells que volen arribar a ser-ho? Les respostes obtingudes a aquesta mena de qüestions no són intranscendents, especialment per a les universitats que formen als futurs mestres. Com s'indica a la Declaració Mundial sobre Educació Superior al segle XXI, un dels documents que major influència ha tingut en la configuració de l'actual formació universitària contemporània, i de manera especial, en la construcció de l'Espai Europeu d'Educació Superior, aquesta educació universitària consisteix en: «formar diplomats altament qualificats i responsables, capaços d'atendre les necessitats de tots els aspectes de l'activitat humana, oferint qualificacions que estiguin a l'alçada dels temps moderns» (UNESCO, 1998). La formació universitària de mestres, per tant, hauria de tenir algun tipus de repercussió en les raons que mouen els estudiants a exercir de mestres, i també en com conceben el mestre qualificat que volen arribar a ser, més encara en un temps en què el món de l'educació està canviant substancialment (Hargreaves, 1994).

L'objectiu d'aquest article és doble: d'una banda, presentar les respostes que els estudiants del Grau d'Educació Primària han proporcionat quan se'ls pregunta per què volen ser mestres i com ha de ser un bon mestre; i de l'altra, elevar una sèrie de consideracions per a la formació universitària d'avui. El treball parteix de les universitats catalanes, insertes en un entorn espanyol i europeu. No obstant això, algunes de les seves conclusions també es podrien estendre a altres realitats universitàries. Abans de presentar l'estudi metodològic, els resultats i les conclusions, esbossarem el marc teòric en el qual es fonamenta la nostra investigació.

\section{Marc teòric}

La recerca del bon mestre comença a la Grècia clàssica (Mcewan, 2011), però encara es manté viva. No podia ser d'una altra manera: l'educació és un assumpte primordial per les nostres comunitats, i per això, «la tasca d'educar determinades coses és delegada a un grup especial de persones» (Dewey, 1916, p. 11). Alguns autors consideren que estem parlant d'alguna cosa més que d'experts que atresoren unes o altres competències professionals i determinades qualitats personals, que estem parlant de persones que encarnen una forma de vida particular i inigualable (Higgins, 2011; Steiner, 2004).

Durant els últims anys s'han dut a terme diverses investigacions al respecte. Grosso modo, les unes han indagat en els perfils dels mestres que exerceixen una major i millor influència educativa i personal en els alumnes (Cooper i McIntyre, 1996); i unes altres s'han centrat en les raons i motivacions que mouen a voler formar part d'aquest grup especial de persones de qual parlava Dewey (Stenberg, Karlsson, Pitkaniemi i Katriina, 2014).

Aquestes investigacions ens situen davant d'un assumpte complex (Korthagen, 2004) $i$ ens permeten construir tres categories o tipologies que defineixen els trets $i$ característiques més rellevants del bon mestre, i les raons o motivacions més destacades per voler arribar a ser-ho. Tot i que no pretenen ser categories excloents, el seu tractament per separat ens serà d'utilitat per al disseny del nostre estudi empíric, 
l'anàlisi dels resultats i les consideracions per a la formació universitària dels futurs mestres.

La primera categoria l'hem anomenada «mestre personal i autèntic». El seu sentit i significat arrela en un passat llunyà (Marrou, 1956). Plató, inspirat en la figura del seu mestre Sòcrates i en la seva crítica a Protàgores, concep el mestre ideal com aquell que busca la seva autenticitat personal establint una relació especial amb el seu alumne (Plató, 2010). Per al propi Plató aquesta relació és d'amor, una cosa que d'una manera o d'una altra s'ha seguit defensant fins als nostres dies (Goldstein, 2000). El mestre, així concebut, és «algú de qui hom pot pensar que li agradaria arribar a ser com ell, fet que no té a veure amb l'ambició sinó amb una cosa semblant a l'amor, a l'eros» (Steiner i Ladjali, 2005, p. 129). Rousseau (1990) parla d'una relació d'amistat i altres autors d'una relació de cura (Noddings, 2010). Sigui com sigui, des d'aquest punt de vista el bon mestre és aquell que estableix una relació educativa que s'assembla a una relació terapèutica, en tant que ell i el seu alumne busquen conjuntament la perfecció de tots dos (Scott, 2000). Aquesta manera de pensar del bon mestre ha estat enfocada des de diversos terrenys, principalment des de l'ètica, la moral o el caràcter (Power, Nuzzi, Narváez, Lapsley i Hunt, 2007), i també des de la identitat personal (Swennen, Jones i Volman, 2010). En fi, aquesta categoria descriu el mestre que combina, d'una banda, la mirada cap a l'alumne en tant que s'implica en la seva vida, en les seves circumstàncies escolars i sobretot personals i, d'altra banda, la mirada cap a ell mateix, en tant que busca el seu propi creixement i autenticitat precisament a través del magisteri.

La segona categoria és la que hem anomenat: «mestre transmissor d'històries». Un bon mestre, sens dubte, és algú que coneix allò que explica (Verlop, Van Driel i Meijer , 2001). No obstant això, aquesta categoria, i segons les investigacions anteriorment citades, necessita un parell de matisacions. La primera és que no es tracta de conèixer només l'àrea de coneixement que és pròpia, ja sigui matemàtiques, biologia o literatura, sinó també altres matèries igualment importants. El bon mestre és una persona que s'embarca en un viatge permanent cap al coneixement (Ayers, 2001) i que, per tant, està interessada per qualsevol qüestió cultural i científica que pogués engrandir les seves Iliçons (Oakeshot, 2009). La segona matisació es refereix al fet que no n'hi ha prou amb conèixer, o fins i tot disposar d'un vast coneixement il.lustrat, allò que hom ha d'explicar, sinó que ha de despertar l'interès cap al coneixement, sigui quin sigui, a través d'aquesta transmissió (Delpit, 2003). Aquest darrer aspecte, com és d'imaginar, té importants conseqüències en l'alumne. Segons Ordine $(2013$, p. 98), «tots hem pogut experimentar fins a quin punt la inclinació cap a una matèria específica ha estat suscitada, amb molta freqüència, pel carisma i l'habilitat d'un professor». En definitiva, el «mestre transmissor d'històries» és aquell que nodreix i engrandeix les seves lliçons amb continguts que estan relacionats amb el que tracta d'explicar. I a més, transmet allò que explica no d'una manera qualsevol, sinó d'una manera que cala, pertorba i inquieta la ment i l'ànima de l'alumne, no només durant un instant sinó durant tota una vida.

La tercera i última categoria I'hem anomenada «mestre motivador per a l'aprenentatge». Aquesta categoria s'arrela en el moviment sofístic (Kerferd, 1981) i es centra en el mètode; és a dir, en el conjunt de competències, habilitats i tècniques que són necessàries per a ensenyar alguna cosa algú. I, sobretot, també es centra 
en motivar l'aprenentatge d'això que s'està tractant d'ensenyar. El bon mestre necessita, doncs, disposar d'un com, d'un procediment adequat que condueixi a la construcció d'autèntics escenaris d'aprenentatge (Martínez i Bujons, 2001). Aquesta manera de concebre el bon mestre ha estat atesa durant els últims anys d'una manera considerable (Woods, 1990; Ritter i Hancock, 2007; Applegate, 2010). A més, els nous reptes que dia rere dia es presenten al món de l'educació escolar provoquen que el com de l'ensenyament estigui en constant moviment. Al costat de les actualitzacions constants de les didàctiques pròpies de cada àrea de coneixement, els mestres han de disposar també d'altres sabers: com ensenyar a gestionar conflictes a l'aula (Morris-Rothschild i Brassard, 2006), com ensenyar a conviure en aules multiculturals (Tartwijk, Brok, Veldman i Wubbels, 2009), com ensenyar a apreciar i valorar la inclusió dels més desfavorits (Jordan, Schwartz i McGhie-Richmond, 2009), com ensenyar a fer ús de les intel-ligències múltiples (Gardner, 1997), com ensenyar de manera conjunta amb altres col·legues (Hargreaves, 2001), etc.

En resum, aquesta categoria es refereix al mestre que domina el com, els mètodes i les tècniques que fomenten els bons aprenentatges, o també es podria dir al mestre que converteix la seva aula, les seves classes i assignatures en espais òptims, motivadors i agradables perquè l'alumnat aprengui més i millor.

\section{Estudi metodològic}

\section{Mètode, disseny i mostra}

La mostra objecte d'estudi d'aquesta investigació es correspon amb estudiants que el 2015 cursaven primer i últim curs del Grau d'Educació Primària en alguna de les deu universitats catalanes ${ }^{3}$. S'ha considerat un mostreig aleatori estratificat amb un criteri d'afixació establert a partir de la universitat d'estudi i el curs de l'alumnat. El conjunt de respostes que configuren la mostra final són 887 que, sobre un univers de 2.901 individus, suposa un error mostral del 2,74\% per a un nivell de confiança del $95 \%$ en el supòsit de màxima variància $(p=q=50 \%)$.

\section{Procés de construcció categorial}

El qüestionari de la investigació és autoadministrat i inclou una bateria de preguntes tancades sobre la universitat construïdes a partir d'una escala Likert d' 1 a 5, preguntes de classificació (edat, sexe, curs i universitat) i, finalment, les dues preguntes obertes que són objecte d'aquest treball: «Per què vols ser mestre?» i «Segons la teva opinió, com ha de ser un bon mestre?». Amb les respostes obtingudes en aquestes dues preguntes obertes es va construir de forma apriorística el sistema de categories abans presentat.

(3) Les universitats públiques són: Universitat de Barcelona (UB), Universitat Autònoma de Barcelona (UAB), Universitat de Lleida (UdL). Universitat de Girona (UdG) i Universitat Rovira i Virgili (URV); les universitats privades són: Universitat Ramon Llull-Blanquerna (URL), Universitat Abat Oliva (UAO), Universitat de Vic-Universitat Central de Catalunya (UVic-UCC) i Universitat Internacional de Catalunya (UIC). Les universitats considerades grans són les que tenen més de 450 estudiants en primer i quart curs (UB i UAB), les mitjanes entre 150 i 450 (UdL, UdG, URV, URL, UVic-UCC) i les petites menys de 150 (UAO i UIC). 
Respecte a la pregunta: «Per què vols ser mestre?», es va dur a terme una codificació de les respostes obertes a partir de criteris semàntics i se n'obtingueren 17 codis que van ser agrupats per construir la categoria de mestre presentada. A aquestes categories s'hi va afegir la de «mestre com a agent de canvi social», entenentho com algú que vol millorar el món educatiu i social, i la de «mestre amb vocació instrumental», com algú que vol gaudir de les condicions laborals i socials de la professió de mestre. En la categoria de «mestre personal i autèntic» s'hi van identificar codis que fan referència al creixement i desenvolupament dels alumnes (mirada cap als alumnes): afinitat pels nens, ajudar els infants, deixar-hi empremta, ensenyar a viure, fomentar la seva felicitat, ser un guia de vida, esdevenir un referent, llinatge professional i vocació pels infants; i també codis que fan referència al propi creixement i desenvolupament personal i professional (mirar-se un mateix): creixement personal, realització personal. A la de «mestre transmissor d'històries» no es va identificar cap codi. D'altra banda, a la de «mestre motivador per a l'aprenentatge» es va identificar el codi: els nens aprenen amb mi. La categoria «mestre agent de canvi social» inclou els codis tals com millorar el món de l'educació, canviar el sistema educatiu o fomentar la transformació social. I, finalment, la categoria «mestre amb vocació instrumental» inclou els codis: bones condicions laborals i flexibilitat horària.

Amb relació a la pregunta «Segons la teva opinió, com ha de ser un bon mestre?» s'obtingueren 34 codis que es van agrupar entre les categories presentades a les quals s'hi va afegir una de nova que anomenem «mestre amb formació permanent», entenent per això el bon mestre que no vol deixar de formar-se al llarg de tota la seva vida professional. A la categoria «mestre personal i autèntic» es van identificar codis que, per l'orientació de les respostes redactades, fan referència únicament a una mirada cap als seus alumnes. Aquests codis són: afectiu, atent, amb autoritat, comprensiu, transmissor de valors, empàtic, entregat, equitatiu, curós amb els infants, igualitari, integrador, que posa límits, pacient, proper, un referent personal, respectuós, responsable, amb vocació pels infants, generós i just. En canvi, a la categoria «mestre transmissor d'històries» s'hi van identificar els codis següents: bon comunicador, crític amb allò que explica, reflexiu i obert a altres formes de veure el món. A la categoria «mestre motivador per a l'aprenentatge» s'hi van identificar els codis següents: que adapta l'ensenyament, que és guia de l'aprenentatge, innovador, flexible amb els ritmes d'aprenentatge, motivador, organitzador del bon aprenentatge, resolutiu davant les dificultats d'aprenentatge i que fomenta el treball en equip entre els alumnes. Finalment, a la categoria «mestre amb formació permanent» s'hi van identificar els codis: formació constant i que s'interessa per les noves formes d'ensenyar.

\section{Resultats}

Les respostes obtingudes en les dues preguntes plantejades no són autoexcloents entre elles, sinó que més aviat són diverses i complementàries. Amb altres paraules, direm que la resposta d'un mateix estudiant a qualsevol de les dues preguntes plantejades acostuma a incloure-hi codis que es corresponen amb categories diferents. Per aquesta raó, metodològicament s'ha optat per un tipus de resposta múltiple en què les dades que es presenten sumen més del 100\%. A continuació exposem els resultats de les dues preguntes per separat. 


\section{Per què vols ser mestre?}

Els estudiants, de forma majoritària $(83,8 \%)$, volen ser un «mestre personal i autèntic» i, a més, presenten una major orientació cap als alumnes (70,3\%) que cap a ells mateixos (48,3\%). És a dir, segons diuen, per ells és més important el creixement i desenvolupament dels seus alumnes que el seu propi. Els resultats també indiquen que els estudiants de primer curs volen ser un «mestre personal $i$ autèntic» en un grau major $(90,8 \%)$ que els de quart curs $(78,4 \%)$, també que tenen una major mirada cap als alumnes $(75,1 \%$ enfront del $66,7 \%)$ i una mirada cap a un mateix més alta (52,9\% i $44,8 \%$ respectivament).

Un $25,1 \%$ d'estudiants volen ser un «mestre motivador per a l'aprenentatge», sense que s'hagin trobat gaires diferències significatives entre primer i quart curs. Els estudiants que volen ser un «mestre agent de canvi social» són una mica més de la quarta part del total $(25,8 \%)$, d'entre els quals destaquen significativament els alumnes de primer curs $(31,2 \%)$ per sobre dels alumnes de quart $(21,8 \%)$. Finalment, els estudiants que diuen voler ser un «mestre amb vocació instrumental» escassament arriben a l'1,5\% del total. Com s'ha esmentat, en aquesta pregunta no s'hi ha trobat cap codi de la categoria «mestre transmissor d'històries».

Taula 1. «Per què vols ser mestre?», per curs de l'alumne (\%)

\begin{tabular}{lccc}
\hline \multirow{2}{*}{ Tipologia de mestre } & $\%$ & \multicolumn{2}{c}{ Curs } \\
\cline { 3 - 4 } & & Primer & Quart \\
\hline Mestre personal i autèntic & 83,8 & $90,8^{*}$ & 78,4 \\
Mirada cap a l'alumne & 70,3 & $75,1^{*}$ & 66,7 \\
Mirada cap a un mateix & 48,3 & $52,9^{*}$ & 44,8 \\
Mestre agent de canvi social & 25,8 & 31,2 & 21,8 \\
Mestre motivador per l'aprenentatge & 25,1 & 26,4 & 24,2 \\
Mestre amb vocació instrumental & 1,5 & 1,3 & 1,6 \\
Mestre transmissor d'històries & - & - & - \\
\hline Base & 887 & 382 & 505 \\
\hline
\end{tabular}

Nota: Resposta múltiple. * $\mathrm{P}<0,05$.

En una anàlisi més detallada de la categoria «mestre personal i autèntic» $s^{\prime} h i$ observen diferències significatives entre els estudiants de les universitats privades $(92,6 \%)$ i les públiques $(80,7 \%)$, i entre els que provenen d'universitats de grandària mitjana $(90,0 \%)$ o petita (90.5\%) i d'universitats de grans dimensions $(77,1 \%)$. Paral-lelament, els estudiants que dirigeixen la seva mirada cap al creixement i desenvolupament personal dels seus alumnes estan més presents a les universitats privades $(76,8 \%)$ que en les públiques $(68,1 \%)$, i en les universitats de mida mitjana $(75,4 \%)$ o petita $(71,4 \%)$ que en les grans universitats $(65,4 \%)$. Una cosa similar passa quan dirigeixen la mirada cap al seu propi creixement personal i professional: està més present entre els estudiants de les universitats privades $(54,4 \%)$ que entre els estudiants de les universitats públiques $(46,1 \%)$, i entre els d'universitats de mida mitjana $(52,4 \%)$ o petita $(54,6 \%)$ que en els de les més grans $(43,3 \%)$.

En relació amb aquesta categoria no es troben diferències significatives de gènere en termes generals, però si es mira el percentatge d'estudiants que manifesten una mirada cap a si mateixos o cap al seu propi creixement personal i professional, 
es comprova com és significativament major el nombre d'homes $(56,7 \%)$ que el de dones (46,4\%), i a l'inrevés: el percentatge que presenta una mirada vers els alumnes és significativament més gran entre les dones (78,6\%) que entre el homes $(72,4 \%)$.

Finalment, i malgrat la poca presència de la categoria que hem anomenat «mestre amb vocació instrumental», es troben diferències significatives entre els estudiants de les universitats privades $(2,6 \%)$ i els de les públiques $(0,9 \%)$.

\section{Com ha de ser un bon mestre?}

Per a la majoria d'estudiants $(71,7 \%)$ un bon mestre ha de ser un «mestre personal i autèntic»; per a pràcticament la meitat $(49,4 \%)$ un bon mestre ha de ser un «motivador per a l'aprenentatge»; per aproximadament un de cada quatre $(24,3 \%)$ ha de ser un «transmissor de històries» $i$, finalment, per un 31,1\% ha de ser un «mestre amb formació permanent». A excepció de la categoria «mestre transmissor de històries», s'hi obtenen diferències significatives en totes les altres si es comparen les respostes dels estudiants de primer i quart curs, on els primers puntuen sempre més alt.

Taula 2. «Com ha de ser un bon mestre?», per curs de l'alumne (\%)

\begin{tabular}{lccc}
\hline \multirow{2}{*}{ Tipologia de mestre } & $\%$ & \multicolumn{2}{c}{ Curs } \\
\cline { 3 - 4 } & & Primer & Quart \\
\hline Mestre personal i autèntic & 71,7 & $79,6^{*}$ & 65,7 \\
Mestre motivador per l'aprenentatge & 49,4 & $57,0^{*}$ & 43,8 \\
Mestre amb formació permanent & 31,1 & $34,6^{*}$ & 28,5 \\
Mestre transmissor d'històries & 24,3 & 26,7 & 22,5 \\
\hline Base & 887 & 382 & 505 \\
\hline
\end{tabular}

Nota: Resposta múltiple. * $\mathrm{P}<0,05$.

En relació amb la categoria «mestre personal i autèntic» es troben diferències significatives entre els estudiants d'universitats públiques $(70 \%)$ i privades $(76,3 \%)$, i entre els de les universitats mitjanes (74,9\%) i petites (74,9\%) i les grans $(67,8 \%)$. En relació amb la categoria «mestre transmissor d'històries», també són els estudiants de les universitats petites $(28,1 \%)$ i mitjanes $(27,1 \%)$ els que més puntuen en relació amb els seus companys de les universitats públiques $(21,1 \%)$.

Entre les categories «mestre motivador per a l'aprenentatge» $\mathrm{i}$ «mestre amb formació permanent» no s'han trobat diferències ni entre la titularitat de les universitats ni tampoc entre la seva grandària. Finalment, val la pena assenyalar que en cap de les categories apareixen diferències significatives entre homes i dones.

\section{Discussió i conclusions}

Les dades obtingudes deixen algunes qüestions sobre la taula i permeten elevar algunes conclusions per a la formació universitària dels futurs mestres d'Educació Primària. 
La primera qüestió destacable és el manifest desequilibri entre les tres categories presentades, o si es prefereix, la contundent aposta per una d'elles. La majoria d'estudiants vol ser un «mestre personal i autèntic» per damunt de tota la resta i considera que un bon mestre és, principalment, algú que actua com a tal. Els resultats obtinguts van en la mateixa línia que bona part de les investigacions citades al marc teòric. Cal preguntar si no és aquest el tipus de mestre al qual es felicita en no poques de les biografies i autobiografies dels grans personatges i al qual s'enalteix en reeixides pel-lícules i, no menys important, si no és veritat que el mateix sentit comú tendeix a valorar aquest tipus de mestre molt més que qualsevol altre.

Ara bé, els estudiants volen ser algú important en les vides dels seus alumnes, molt més que créixer com a persones i professionals. I tot sigui dit, això és més freqüent entre les dones que entre els homes, qüestió que està en la mateixa línia que la literatura que tracta l'assumpte (Gilligan, 1982; Acker, 1995). La sobrevaloració de la mirada cap als alumnes en detriment de la mirada cap a un mateix no pot passar desapercebuda. Lluny del que es pugui pensar, la influència educativa i personal que un mestre exerceix entre els seus alumnes no se sustenta únicament ni principalment en qüestions com la vocació pels infants o en el voler deixar empremta, sinó també en el creixement i el desenvolupament personal, l'autoconeixement i l'autocomprensió (Steiner, 2004). El bon mestre és, sobretot, un bon mestre per a ell mateix, i això té molt a veure, per dir-ho d'una manera resumida, amb la formació de la persona, amb el seu caràcter. On queda aquesta formació a la universitat d'avui? El títol de mestre que atorguen les nostres universitats, garanteix que s'hagi assolit la qualitat i la qualitat humana necessària per a exercir tal professió? L'adquisició d'un caràcter que influeixi educativament i personalment en els alumnes no queda solucionada amb la vocació, ni tan sols coberta amb el domini de les anomenades competències personals (OECD, 1997; González i Wagenaar, 2003). Al nostre entendre suposa una mica més que això.

Aquestes consideracions ens condueixen, si més no, a dues conclusions. La primera és que la formació de mestres cal que consideri com a importants els continguts que conviden a pensar en un mateix com a futur mestre, on es presenten a grans mestres de la història que es van pensar i van construint-se d'una manera excepcional (Château, 1959); en definitiva, continguts que remouen i il-luminen les ments i ànimes dels estudiants. Aquests continguts que són propis de la teoria de l'educació, l'antropologia de l'educació, la filosofia de l'educació, la història de l'educació o àrees per l'estil potser no són rendibles en un sentit postmodern, però sí que són tremendament útils. La segona conclusió té a veure amb l'aprofitament de la tutoria universitària (Walton, 1972). És aquesta una excel-lent eina pedagògica i universitària per fomentar la formació del caràcter dels estudiants, i és preocupant que en no poques ocasions hagi quedat reduïda a una qüestió opcional i puntual de la qual es fa ús com si d'una finestreta de reclamacions es tractés.

La segona qüestió és la significativa devaluació que pateixen pràcticament totes les categories entre els estudiants de primer i quart curs. Els estudiants haurien de voler ser més «mestres personals i autèntics», més «mestres transmissors d'històries» o més «mestres motivadors per a l'aprenentatge» al final que al principi del seu periple universitari, però succeeix tot el contrari. Ens atrevim a dir que té molt a 
veure amb el desencantament social sobre la formació universitària actual (Hernández, Delgado-Gal i Pericay, 2013), una cosa que ve de lluny (Bloom, 1987) i que també inclou els estudiants de magisteri. Per descomptat, no s'està criticant l'actual formació universitària de mestres, perquè les categories sobre el bon mestre i el voler ser-ho es mantenen presents des del principi fins el final. El que s'està assenyalant més aviat és que les bones raons i concepcions amb les que els estudiants accedeixen a la universitat no només no es veuen reforçades, sinó que s'afebleixen a mesura que passen els anys. La formació de mestres, i aquesta és la nostra tercera conclusió, hauria de prendre les mesures que fossin necessàries per adquirir la forma d'experiència vital, de transformació personal i no només una carrera d'obstacles normalment anomenades assignatures o cursos (Delbanco, 2012).

La tercera qüestió té a veure amb la categoria del «mestre com a transmissor d'històries». Sorprèn que no destaqui en la concepció que es té de qui és un bon mestre i desconcerta que ni tan sols aparegui entre les raons per les quals els estudiants volen ser mestres. En aquesta categoria s'hi presenten dues qüestions importants: d'una banda l'oratòria, eloqüència, o usualment anomenades tècniques de comunicació que se li suposen a un bon mestre, i d'altra banda el coneixement exhaustiu de tot allò que ajudi el mestre a explicar allò que ha d'explicar. La formació universitària actual s'ha ocupat del primer dels aspectes, perquè els moments en què els estudiants han d'expressar-se en públic són molts i és d'imaginar que els professors universitaris tracten d'avaluar si això es realitza d'una manera competent. El segon aspecte, però, no té la mateixa sort i és que la formació del mestre culte, no tant la d'aquell que adquireix un coneixement enciclopèdic, sinó d'un saber humanístic i liberal (Perry, 1970; Bloom, 2005), no sembla rebre l'atenció que mereix. Sembla que no ens acabi de convèncer que les lliçons d'un mestre, sigui de la matèria que sigui, s'enriqueixen quan per exemple s'ha llegit la llíada o l'Odissea d'Homer o La muntanya màgica de Thomas Mann, s'ha contemplat la volta de la Capella Sixtina de Miguel Àngel o Las Meninas de Velázquez, s' ha escoltat de la primera a la novena simfonia de Beethoven o la discografia dels Beatles, s'ha vist el Somni d'una nit d'estiu de Shakespeare o Dotze homes sense pietat de Reginald Rose, Ciutadà Kane o Matrix, o El barber de Sevilla de Rossini o La traviata de Verdi. Els futurs mestres també s'haurien de submergir en aquesta mena de cultura, en aquests moments estel.lars de la humanitat (Zweig, 2002), qüestió que sembla indiscutible atès que tot això facilita que l'autèntica influència educativa i personal entre els alumnes sigui efectiva. Aquesta és la nostra quarta conclusió: la formació en la cultura hauria de ser quelcom més que una qüestió d'elecció personal o l'oferiment de cursos, seminaris i conferències de caràcter optatiu; més aviat haurien d'estar contemplades en els plans d'estudi de les nostres facultats d'Educació.

La quarta qüestió té a veure amb les diferències existents entre els estudiants d'universitats grans i els d'universitats mitjanes o petites. La gran majoria de categories analitzades puntuen més alt en els estudiants de quart curs de les de menor grandària. Aquests resultats confirmen una lògica suposició i és que la formació de mestres necessita un considerable nivell de treball conjunt entre professors i estudiants i, per tant, un elevat grau de relació personal. Es podria argumentar que qüestions com la ràtio d'estudiants per professor o la disposició i repartició de recursos, encara que ambdues qüestions hagin millorat durant els últims anys, perjudica les grans universitats. No obstant això, hi ha una altra qüestió que mereix més atenció 
encara i és que les de grandària mitjana i petita són universitats que estan en millors condicions per aprofundir en el treball de les categories presentades, no tant perquè tinguin menys estudiants que atendre, amb tots els avantatges que això suposa, com perquè els seus reduïts claustres tenen més condicions de possibilitat de reflexionar sobre quin projecte formatiu ofereixen als seus estudiants. Aquest fet augmenta encara més en les universitats privades. En elles, siguin confessionals o no, s'assumeix en bona mesura que l'estudiant és un tipus de client que paga un considerable preu per la seva formació i, per tant, sol-licita una atenció de qualitat. Sobre tot aquest assumpte presentem l'última de les nostres conclusions.

És important que el treball en equip del professorat de les facultats d'Educació contempli entre els seus principals objectius haver d'aprofundir en la qüestió de com ha de ser un bon mestre i com enfortir les metodologies per arribar a ser-ho. Aquest treball aniria més enllà de, per exemple, organitzar assignatures, llistar competències o acordar metodologies pedagògiques, sinó que més aviat és un treball de reflexió filosòfica (Higgins, 2011). Es necessita que la reflexió compartida del professorat universitari sigui tinguda en compte d'una manera important, tant amb relació a la investigació, gestió i qüestions burocràtiques que avui col-lapsen les agendes del professorat universitari (Firestone i Bader, 1991), com amb relació a les acreditacions oficials que avui dia avaluen la tasca acadèmica.

\section{Referències}

Acker, S. (1995) «Carry on caring: the work of women teachers». British Journal of Sociology of Education, 16, p. 21-36.

Applegate, J. R. (2010) «Teaching Competencies and the Teacher Preparation Program». Improving College and University Teaching, 25 (4), p. 226-230.

Ayers, W. (2001) To Teach: The Journey of a Teacher. New York, Teachers College Press.

Bloom, A. (1987) The closing of American mind. New York, Simon and Schuster.

Bloom, H. (2005) ¿Dónde se encuentra la sabiduría? Madrid, Taurus.

Bricheno, P. i Thornton, M. (2007) «Role Model, hero or champion? Children's views concerning role models». Educational Research, 49 (4), p. 383-396.

Château, J. (1959) Los grandes pedagogos. México, D. F., Fondo de Cultura Económica.

Cooper, P. i Maclntyre, D. (1996) Effective teaching and learning: Teachers' and students' perspectives. Buckingham, Open University Press. Delbanco, A. (2012) College, What it was, is, and should be. New Jersey, Princeton University Press.

Delpit, L. (2003) «Educators as "seed people" growing a new future». Educational Researcher», 32 (7), 14-21.

Dewey, J. (1916) Democracy and Education. New York, Macmillan Company.

Firestone, W. A. i Bader, B. D. (1991) «Professionalism or Bureaucracy? Redesigning Teaching». Educational Evaluation and Policy Analysis, 13 (1), p. 67-86.

Fry, H.; Ketteridge, S. i Marshall, S. (2009) A Handbook of teaching and learning in Higher Education. Enhancing academic practice. New York, Routledge.

Gardner, H. (1997) «Teaching for multiple intelligences». Educational Leadership, 55 (1), p. 9-13. 
Gilligan, C. (1982) In a Different Voice: psychological theory and women's development. Cambridge, Harvard University Press.

Goldstein, L. S. (2000) «Love, love and more love for children: exploring preservice teacher's understandings of caring». Teaching and Teacher Education, 16 (8), p. 861-872.

González, J. i Wagenaar, R. (eds.) (2003) Tuning Educational Structures in Europe. Final Report. Phase One. Bilbao, Universidad de Deusto.

Hargreaves, A. (1994) Changing Teachers, Changing Times: Teacher's Work and Culture in the Postmodern Age. London, Continuum.

Hargreaves, A. (2001) «The Emotional Geographies of teachers' relations with colleagues». International Journal of Educational Research, 35 (5), p. 503-527.

Hernández, J.; Delgado-Gal, A. i Pericay, X. (2013) (Eds.) La universidad cercada. Testimonios de un naufragio. Barcelona, Anagrama.

Higgins, C. (2011) The good life of teaching. An Ethics of Professional Practice. Oxford, Wiley-Blackwell.

Jackson, P.W. (1986) The Practice of Teaching. New York, Teachers College Press.

Jaeger, W. (1981) Paideia: Los ideales de la cultura griega. Madrid, Fondo de Cultura Económica.

Jordan, A.; Schwartz, E. i McGhie-Richmond, D. (2009) «Preparing teachers for inclusive classrooms». Teaching and Teacher Education, 25(4), p. 535-542.

Kerferd, G. B. (1981) The Sophistic Movement. New York, Cambridge University Press.

Korthagen, F. (2004) «In search of the essence of a good teacher: towards a more holistic approach in teacher education». Teaching and Teacher Education, 20 (1), p. 77-97.

Marrou, H. I. (1956) A History of Education in Antiquity. New York, Sheed and Ward.

Martínez, M. i Bujons, C. (2001) (Ed.) Un lugar llamado escuela. Barcelona, Ariel.

Mcewan, H. (2011) «Narrative reflection in the Philosophy of Teaching: Genealogies and Portraits». Journal of Philosophy of Education, 45 (1), p. 125-140.

Morris-Rothschild, B. K. i Brassard, M. R. (2006) «Teachers conflict management styles: The role of attachment styles and classroom management». Journal of School Psychology, 44 (2), p. 105-121.

Noddings, N. (2010) "Moral education and caring». Theory and Research in Education, 8 (2), p. 145-151.

Oakeshott, M. (2009) La voz del aprendizaje liberal. Buenos Aires, Katz Editores.

OECD (1997) DeSeCo Project. Definition and Selection of Competencies: Theoretical and Conceptual Foundations. Paris, OECD.

Ordine, N. (2013) La utilidad de lo inútil. Manifiesto. Barcelona, Acantilado.

Perry, W. (1970) Forms of Ethical and Intelectual Development in the College Years. A Scheme. San Francisco, Jossey-Bass.

Platón (2010) Protágoras. Madrid, Editorial Gredos.

Power, F. C.; Nuzzi, R. J.; Narváez, D.; Lapsley, D. K. i Hunt, T. C. (2007) (Eds.) Moral Education. A handbook. Volume one. Westport, C.T., Praeger.

Ritter, J. T. i Hancock, D. R. (2007) «Exploring the relationship between certification sources, experience levels, and classroom management orientations of classroom teachers». Teaching and Teacher Education, 23(7), 1206-1216. 
Rousseau, J.-J. (1990) Emilio, o De la educación. Madrid, Alianza Editorial.

Scott, G. A. (2000) Plato's Socrates as Educator. New York, Suny Press.

Sennet, R. (2009) El artesano. Barcelona, Anagrama.

Steiner, G. (2004) Lecciones de los Maestros. Madrid, Siruela.

Steiner, G. i Ladjali, C. (2005) Elogio de la transmisión. Madrid, Siruela.

Stenberg, K.; Karlsson, L.; Pitkaniemi, H. i Katriina, M. (2014) «Beginning student teacher's teacher identities based on their practical theories». European Journal of Teacher Education, 37 (2), p. 204-219.

Swennen, A.; Jones, K. i Volman, M. (2010) «Teacher educators: their identities, subidentities and implications for professional development». Professional Development in Education, 36 (1-2), p. 131-148.

Tartwijk, J.; Brok, P.; Veldman, I. i Wubbels, T. (2009) «Teachers' practical Knowledge about classroom management in multicultural classrooms». Teaching and Teacher Education, 25 (3), p. 453-460.

UNESCO (1998). Declaración Mundial sobre Educación Superior en el siglo XXI. [online] Disponible a:

http://www.unesco.org/education/educprog/wche/declaration_spa.htm [Accés 5 Sep. 2019].

Verlop, N.; Van Driel, J. i Meijer, P. (2001) «Teacher Knowledge and the Knowledge Base of Teaching». International Journal of Educational Research, 35/5, p. 441461.

Walton, A. J. (1972) Lectures, Tutorials and the Like. Oxford, MTP Publishing.

Woods, P. (1990) Teacher Skills and Strategies. Basingstoke, Falmer Press.

Zweig, S. (2002) Momentos estelares de la humanidad. Barcelona, Acantilado. 


\section{¿Por qué quieres ser maestro? ¿Cómo es un buen maestro? Ideas para la formación universitaria}

Resumen: Este trabajo se centra en el colectivo que precisamente se está formando como maestro, concretamente en los estudiantes del Grado de Educación Primaria de las universidades catalanas. Se presentan los resultados que se obtienen cuando se les pregunta por qué quieren ser maestros y cómo es un buen maestro, y se plasman algunas consideraciones para la formación de maestros en la universidad de hoy. Se utiliza la metodología cuantitativa, mediante un cuestionario autoadministrado, en una muestra representativa con preguntas abiertas recodificadas a posteriori. A partir de las investigaciones de mayor incidencia, se han construido tres principales categorías. La primera es el maestro personal y auténtico, entendiendo por ello al maestro que ejerce una influencia en sus estudiantes por su carácter o manera de ser; la segunda es el maestro transmisor de historias, entendiendo por ello al maestro que explica las lecciones de tal manera que difícilmente se olvidan; y la tercera es el maestro motivador para el aprendizaje, entendiendo por ello al maestro que organiza espacios y momentos en los que los alumnos consiguen aprender con cierta facilidad y entusiasmo. Esta evidencia, junto a otras que la complementan, permite ofrecer algunas consideraciones para la formación universitaria de los futuros maestros.

Palabras clave: Formación universitaria, Espacio Europeo de Educación Superior (EEES), Grado de Educación Primaria, influencia educativa.

\section{Pourquoi voulez-vous enseigner ? À quoi reconnaît-on un bon enseignant? Des idées pour la formation universitaire}

Résumé: Ce travail, centré sur un collectif qui suit une formation d'enseignant, analyse concrètement les étudiants du grade d'enseignement primaire des universités catalanes. II présente les réponses obtenues auprès des enseignants sur les raisons pour lesquelles ils veulent enseigner et sur la définition d'un bon enseignant. L'article présente également quelques considérations importantes pour la formation actuelle des enseignants à l'université. Cette analyse utilise la méthodologie quantitative à travers un questionnaire autogéré réalisé auprès d'un échantillon représentatif, avec des questions ouvertes et recodifiées par la suite. À partir des principales enquêtes réalisées, trois catégories principales sont constituées. La première est celle de l'enseignant personnel et authentique, autrement dit de l'enseignant qui exerce une influence auprès de ses étudiants en raison de son caractère ou de sa façon d'être; la deuxième catégorie d'enseignant est celle du passeur d'histoires, autrement dit de celui qui explique les leçons d'une manière qu'on oubliera difficilement ; et la troisième catégorie est celle de l'enseignant qui stimule l'apprentissage et qui aménage des espaces et des moments pour que l'élève puisse apprendre plus facilement et avec enthousiasme. Cette évidence, ainsi que d'autres qui viennent la compléter, permet d'avancer quelques considérations utiles pour la formation universitaire des futurs enseignants.

Mots clés: Formation universitaire, espace européen de l'enseignement supérieur (EEES), grade d'enseignement primaire, influence éducative.

\section{Why do you want to be a teacher? What makes a good teacher? Ideas for teacher training in higher education}

Abstract: This article focuses on teacher training in higher education, specifically on the education students studying the Catalan Bachelor's Degree in Teacher in Primary Education. It reports on the results of a survey asking students why they wanted to be teachers and what they thought made a good teacher. It also reflects on the current state of teacher training at universities today. To complete the research, quantitative data was collected using a self-administered questionnaire containing open-ended, pre-coded questions completed by a representative sample of students. Drawing from the results, the researchers created three main categories of teacher: the first was the personable and authentic teacher, the professional who exerts an influence on students by virtue of their character 
or personality; the second was a narrator of stories, meaning the person who teaches lessons in a such way that they become memorable; and the third was a motivator for learning, meaning the teacher that is able to organise spaces and times in ways that help students learn with ease and enthusiasm. These and the other findings should offer food for thought for the teacher trainers in higher education.

Keywords: Teacher training in higher education, European Higher Education Area (EHEA), bachelor's degree in teacher in primary education; educational influence. 